\title{
The Relationship between Serum Levels of Vitamin C, Uric Acid and Antioxidant status with Coronary Artery Disease: a Case-Control Study
}

Aida Torkzaban

Isfahan University of Medical Sciences

Seyed Amir Mansour Alavi Naeini ( $\sim$ Amalavi@tums.ac.ir)

Isfahan University of Medical Sciences https://orcid.org/0000-0003-1589-9795

Akbar Hassanzadeh

Isfahan University of Medical Sciences

Mehrdad Namdari

Lorestan University of Medical Sciences

Research article

Keywords: vitamin C, uric acid, antioxidant condition, coronary artery diseases

Posted Date: April 15th, 2020

DOI: https://doi.org/10.21203/rs.2.15439/v2

License: (c) (i) This work is licensed under a Creative Commons Attribution 4.0 International License.

Read Full License

Version of Record: A version of this preprint was published at Clinical Nutrition Research on January 1st, 2020. See the published version at https://doi.org/10.7762/cnr.2020.9.4.307. 


\section{Abstract}

Background: Coronary Heart Disease (CHD) is among the main causes of death in adults. Increase of oxidative stress and defects in antioxidant defense play a major role in endothelium performance and are an effective factor in progress of atherosclerosis. The aim of this study is to measure the serum level of UA and vitamin $\mathrm{C}$ as well as the antioxidant status of $\mathrm{CHD}$ patients to evaluate their relationship and compare them with the healthy individual.

Materials and methods: The present case-control study was performed on 44 cases and 44 controls. Demographic data and anthropometric indices were measured. Food frequency questionnaire (FFQ) and international physical activity questionnaire were also completed. After 12 hours of fasting, $10 \mathrm{ml}$ blood was sampled from the participants. Uric acid (UA), vitamin C, TAC and MDA were also measured. The data were finally analyzed by SPSS Ver 22 software.

Results: A significant difference was observed between the two groups in terms of uric acid $(P<0.001)$ and vitamin $C(P<0.03)$. However, mean MDA and TAC showed no significant difference between the two groups. The two groups' difference in terms of vitamin $A, E$ and beta carotene, zinc and selenium intake was not significant. A significant difference was however detected between the two groups in terms of vitamin $C$ intake $(P<0.047)$. A significant relationship was also observed between the systolic blood pressure and $\mathrm{CHD}(\mathrm{P}<0.028)$.

Conclusion: Our results suggest that increasing of serum uric acid and a decrease in serum vitamin $\mathrm{C}$ level can be considered as risk factors for CHD patients. Due to the lack of significant correlation between TAC and CHD in this study, it seems that different results will be obtained with increasing sample size.

\section{Background}

Coronary Artery Disease (CAD) refers to a chronic disease which can remain symptom-less for years [1]. CAD is the first cause of death in today's societies. Moreover, this disease can lead to high mortality and morbidity rates resulting in working and production disability of individuals. Furthermore, it accounts for the highest rank of health costs. Clinical spectrum of CADs includes silent ischemia (symptom-less), chronic stable angina, unstable angina, acute myocardial infarction, ischemic cardiomyopathy, sudden heart death, cardiac arrhythmia and cardiogenic shocks [2]. This disease accounts for $30 \%$ mortality cases all over the world [3]. In Iran, this disease has the first rank among the death-causing diseases with the mortality rate of 33-38\% [4]. Various factors are involved in CAD development which can be divided into modifiable and non-modifiable factors. The non-modifiable factors include high age, gender and family history of CAD; while the modifiable factors encompass smoking, high blood pressure (HBP) and diabetes mellitus [5]. High serum level of uric acid (UA) is one of the risk factors in emergence of cardiovascular incidents. UA is an inflammation factor which can increase the cardio-related deaths in acute coronary syndrome patients by 4.5 times [2]. The relationship between serum levels of uric acid and progress of cardiovascular diseases has been reported for more than 50 years. Despite the significant 
correlation between the UA levels and coronary atherosclerosis suggested in previous studies and recognition of high UA as a risk factor for coronary artery damages, it is not clear whether UA is an independent cause of CAD or it depends on other cardiovascular risk factors [6]. A meta-analysis showed that hyperuricemia can increase the risk of $\mathrm{CHD}$ independent of other common risk factors [7]. Total antioxidant capacity refers to a series of compounds which can protect the biological systems against the adverse impacts of oxygen and nitrogen reactive species. In fact, antioxidants play a crucial role in inhibition of these reactive species and preventing from their formation [8]. Epidemiologic studies have revealed that treatment with antioxidants such as vitamin $C$ and antioxidant-containing foods can decline the inflammation markers and hence decrease the risk of CHDs [9]. Pharmacological doses of vitamin $\mathrm{C}$ stimulate the secretion of nitric oxide (NO) from endothelium and hence can expand the vessels in coronary arteries. This in turn can decline the risk of cardiovascular diseases which is not definite. Numerous studies have revealed that high vitamin $\mathrm{C}$ levels have inverse relationship with serum UA level [10]. Regarding the pathogenic role of oxidative stress and its components in incidence of cardiovascular complications, as well as talking about the role of vitamin $\mathrm{C}$ and $\mathrm{UA}$, on the other hand the modifiable risk factors of cardiovascular diseases with high rate of prevalence, this study is aimed to measure the serum level of UA and vitamin $\mathrm{C}$ as well as the antioxidant status of CAD patients to evaluate their relationship and compare them with the healthy individual considered as the control group.

\section{Methods}

This case-control study was conducted in the angiography Department of Shahid Madani Hospital in Khorramabad, Iran. The case and control group underwent coronary angiography and based on the results of angiography, 44 patients with coronary artery disease (27 men and 17 women with age range of 38-72 having the mean age of 58.58 .1 ) were selected as case group and 44 healthy individuals ( 26 men and 18 women with age range of $35-70$ and mean age of 56.2 8.5) were selected as control group. This research was approved by ethical committee of Isfahan University of Medical Sciences with the ethic code of IR.MUI.RESEARCH.REC.1397.357. Simple sampling method was employed and all the patients had more than $50 \%$ stenosis in at least one of their major coronary arteries confirmed by a cardiologist using coronary artery angiography. Based on the number of involved vessels, 16 patients had single-vessel disease and 28 patients had multi-vessel disease. The control group were selected among the people with no coronary artery stenosis. Control group individuals were matched by the case group in terms of age, sex, BMI, geographical region and physical activity. Exclusion criteria included gout, LeschNyhan syndrom, type II diabetes, malnutrition, pregnancy during the study, cardiomyopathy, previous myocardial infarction, unstable angina, history of congenital cardiac disorder, history of UA metablism disorder, history of oxalate renal stones, renal function disorder (GFR $<30 \mathrm{ML} / \mathrm{min}$ ), liver diseases, multiple sclerosis disease, any treatment for lowering serum UA, hypothyroidism, consumption of vitamin $\mathrm{C}$ supplement and antioxidant supplements in last month. The confusing conditions and diseases were evaluated by examination and investigation of the medical files of the patients and if they were positive, the patient was excluded. The qualified individuals were entered into the study after explaining the goals of the study and written informed consent was signed by every patient or her/his legally authorized 
representative prior to study participation. Data collection was conducted by questionnaires, interviewing, blood sampling and investigation of the patients' files. The general information and demographic data were collected by a questionnaire as well as their oral responses. The participants' physical activity was measured by international physical activity questionnaire (IPAQ). Their antioxidant (beta carotene, vitamin $\mathrm{C}$, E, selenium and zinc) intake was determined by food frequency questionnaire (FFQ). To obtain the normal food intake of the participants in the last year, the frequency of consumption of a specific type of food during a day, week, month or year was asked. By entering the values in an excel file, the consumption rate of each nutrient (in grams) was obtained and entered in a SPSS software. Using an excel file designed based on N4 software, the nutrient amounts of each participant was measured. The blood pressure of the particiapnts was also measured initially their enterance to the angiography department according to the method suggested by WHO. In this method, the patients were let rest for 15 min and their pressure was measured twice in a sitting position from their right hand; the mean of these two measuremens was recorded as the blood pressure [11]. The fasting blood samples of the two groups were collected from 7:30 to 9:00 am and transferred to EDTA tubes. To prepare serum, the samples were centrifuged for $10 \mathrm{~min}$ at $3000 \mathrm{~g}$. The obtained serum was transferred to three capped microtubes to evaluate serum levels of MDA, TAC and vitamin C. the samples were then kept at - 80 until the analysis. The uric acid tests had been previously conducted by an enzymatic method using commercial kits (Pars Azmoon, Tehran, Iran) and the data were available in the files. The measurements were conducted one day prior to angiography after 12 hours of fasting. Vitamin C, MDA and TAC measurements were conducted using the kits of Kiazist Company (Hamedan, Iran) in the biochemistry lab of faculty of nutrition, Isfahan University of Medical Sciences.

The quantitative variables were reported as mean standard deviation (SD). To compare the data of the two groups, independent $T$ test was employed. The data correlation was assessed by Pearsons correlation coefficient. The results were considered significant if $p \leq 0.05$. SPSS-22 software was used for data analysis.

\section{Results}

As table1 suggests, the age range of case and control groups was 38-72 and 35-70, respectively. Their mean age $(p=0.20)$, height $(p=0.82)$, weight $(p=0.9)$ and $B M I(p=0.86)$ were not significantly different. The mean physical activity of the healthy subjects was significantly higher than the patients $(p=0.027)$; while the mean systolic BP of the patients was higher than the healthy subjects $(P=0.028)$. Moreover, their mean diastolic BP was not significantly different $(p=0.39)$.

Table 2 lists the demographic data of the participants. Accordingly, the frequency distribution of the sex $(p=0.83)$, job ( $p=0.83)$ and marital status $(p=0.5)$ was not significantly different between the two groups. Based on Chi square test, the frequency distribution of background diseases was not significantly different between the two groups $(\mathrm{p}=0.37)$. The frequency distribution of residence region of the two groups was not significantly different $(p=0.5)$. Furthermore, Mann-Whitney test showed no significant 
difference in the education level $(p=0.26)$ and monthly income $(p=0.64)$ of the two groups. The frequency of smoking $(p=0.01)$ and medication $(p<0.001)$ of the patients was significantly higher than the controls.

Table 3 summarizes the dietary antioxidant intake in the two groups. As it can be seen, the mean vitamin $C$ intake of the patients was significantly higher than the healthy subjects $(p=0.047)$. The level of other micronutrients intake was not significantly different between the two groups $(p>0.05)$.

Serum levels of biochemical variables were compared with CAD in Table 4. The mean level of vitamin $C$ was significantly higher in healthy subjects $(p=0.03)$. Moreover, the mean level of UA the patients was higher than the healthy controls $(P<0.001)$. Therefore the serum levels of vitamin $C$ and UA showed a significant relationship with CAD. According to the results, although the mean TAC of the case group was higher than the controls, this difference was not significant $(p=0.06)$. MDA was not significantly different between the two groups $(p=0.25)$.

According to the Pearson correlation coefficient ( $r$ ), the UA level has a direct relationship with the TAC; it however showed an inverse relationship with the vitamin A, Zinc and Selenium dietary intake. No other significant relationship was observed between the uric acid and other mentioned variables in Table 5 $(p>0.05)$.

\section{Discussion}

This study evaluated the serum levels of vitamin C, UA and Antioxidant status in 44 angiographicallyconfirmed CHD patients and compared them with 44 controls. The findings revealed that UA and vitamin $C$ were significantly correlated to CAD while TAC and MDA showed no significant relationship with CAD.

\section{Uric acid and CAD}

Uric acid is the product of purine catabolism which can disturb the endothelial function of arteries and increase atherosclerosis by production of nitric oxide, proliferation of flat vascular muscles and increase of insulin resistance [12]. This study indicated that the mean uric acid level of the patients was higher than the healthy individuals $(p<0.001)$ which is in line with the findings of Bagheri et al. [13]. According to Pearson correlation coefficient, the uric acid level had a direct relationship with the TAC $(P<0.001)$. It however exhibited an inverse relationship with vitamin $A(P=0.03)$, Zinc $(P=0.003)$ and Selenium $(P=0.004)$.

Although Framingham analysis and Aric study $[14,15]$ showed no relationship between the uric acid and CAD, numerous studies have reported a possible relationship between uric acid and incidence and severity of CAD [16-20]. Previous studies have reported the increased levels of uric acid in CAD patients. Kim et al. investigated the relative risk of CAD with increase of blood UA in a meta-analysis on 26 cohort studies on about 400000 adults [21]. Ekici et al. showed that the serum level of UA is independently related to the severity and complexity of CAD [22]. In Iran, Goodarzinejad et al. conducted an observational study in Tehran and showed the independent relationship of hyperuricemia with CAD only 
in men [23]. In some other studies, a significant relationship was observed in blood uric acid level and CAD just among women [24-26].

Despite these evidences and the complex relationship between uric acid and other known risk factors of CAD such as metabolic syndrome, obesity, diabetes and chronic renal disease $[27,28]$, it is not clear yet whether the elevated levels of uric acid is an independent risk factor or just a consequence or only an index of CAD.

\section{Vitamin $C$ and CAD}

Results of this study indicated that the mean serum level of vitamin C was significantly higher in healthy individuals compared to the patients. The vitamin C intake of the patients was however higher than the healthy subjects while no significant difference was observed between the two groups in terms of vitamin $E$ and $A$, beta-carotene, $\mathrm{Zn}$ and Se. Better nutritional condition of the patients in this study could be due to higher dietary intake. As these people were aware of their disease, they might attempt to improve their condition by changing their diets.

Serdar et al. [29] and Delport et al. [30] showed the declined levels of plasma antioxidant (including vitamin $\mathrm{A}, \mathrm{C}$ and $\mathrm{E}$ ) in CHD patients. Nojiri et al. studied the oxidative stress in CHD patients by evaluating the level of vitamin A,C and E as well as TAC in a case-control study. Their results indicated a decline in TAC and an increase in vitamin E [31]. Epidemiologic studies have revealed that treatment with antioxidants such as vitamin $\mathrm{C}$ and antioxidant-containing foods are related to decrease of inflammation markers and reduced risk of coronary heart incidents [32, 33].

\section{TAC and CAD}

Increase of oxidative stress and defects in the antioxidant defense system plays a major role in endothelium function disorders and have been considered as the contributing factors in atherosclerosis progress [34]. Investigations on the relationship between the antioxidants and CAD are conflicting. In the present study, although the mean of TAC was higher in the patients group, this difference was not significant; hence it can't be claimed that TAC is related to CAD. In a cross sectional study on 968 adults, no significant difference was observed in TAC and antioxidant enzymes activity of CAD group; uric acid and MDA were however increased in the CAD group [35]. In the work of Bagheri et al., CAD patients had higher UA and TAC compared to the control group; their HDL cholesterol was however decreased. TAC and its main factor (UA) were significantly associated with the prevalence and severity of CAD [13]. In a study by Gawron-Skarbek et al. [36], it was revealed that the CHD patients have higher levels of both TACFRAS and TAC-DPPH. In conterary, Khaki Khatibi et al. [37] showed that the TAC of the CHD patients is significantly lower than the healthy controls.

One of the reasons for lack of significant relationship or increase of TAC in CAD patients could be due to the difference in the TAC measurment methods such as FRAP, which increased UA level, is one of the causes of increase this variable. Increase of UA level in CAD patients was reported in the previous studies. 


\section{MDA and CAD}

MDA is the by-product of fatty acids oxidation with more than two double bonds. Enhanced lipid peroxidation and LDL oxidation are involved in CAD pathogenesis [38]. MDA was also measured. This study showed no significant difference in the plasma levels of MDA (as an index of lipid peroxidation) of the two groups. This is in line with the findings of Bagheri et al. [13]. Serdar et al. also reported enhanced levels of MDA in plasma and red blood cells in CHD patients [29]. Khaki Khatibi et al. [37] and Uppal et al. [39] also revealed the significant increase in MDA of the patients in comparison with the controls. Lee et al. [40] also indicated that MDA level of CAD patients was higher than the controls. Moreover, another studies also reported an increased level of plasma MDA among these patients [31,41].The previous studies generally indicated a direct relationship between CAD and MDA.

Study limitations

Several limitations of our study have also to be addressed. The first limitation is the small sample size. Second, although most potential confounders were carefully controlled, since some of the study subjects may had several chronic disease, we could not eliminate the possible effect of underlying diseases and medications used for these diseases on the present findings.

More perspective studies with large sample sizes and using other markers of oxidative stress are essential to confirm these findings.

\section{Conclusions}

Overall, the current study showed a significant relationship between the serum levels of UA and vitamin C with CAD. According to the findings, CAD patients possess higher UA and lower vitamin $C$ levels in comparison with the healthy subjects. Concerning the association between CAD and TAC, although the TAC of the CAD patients was higher than the controls, this difference was not statistically significant. Results of this study showed that plasma MDA level, as an index of lipid peroxidation, exhibited no significant difference between the two groups. Mean vitamin $\mathrm{C}$ intake of the patients was significantly higher than the healthy subjects. The mean of vitamin E and A, betacarotene, Se and Zn intake showed no significant difference between the two groups. The other results was the direct association of UA and TAC. But relationship with vitamin A, Zn and Se intake was however inverse. There was no significant relationship between UA and vitamin $C$ and MDA and vitamin $C, E$ and betacarotene intake. Findings of this study were also indicative of a relationship between the physical activity and increase of systolic BP as well as no relationship between the education level, job, age, height, weight and BMI with CAD.

\section{Declarations}

\section{Acknowledgements}

The authors thank the support of Isfahan University of Medical Sciences (IUMS). 


\section{Authors' contributions}

The authors' contributions are as follows: All authors have participated in the work and have reviewed and agree with the content of the article. All authors have read and approved the manuscript. AMA conceived and developed the idea for the paper, helped to draft and revised the manuscript and approved the final manuscript. AT contributed to data collection, measurement of biochemical tests and interpretation of the data and wrote numerous drafts; revised the manuscript, and approved the final manuscript. AH contributed to data analysis, MN Cardiac Advisor.

\section{Funding}

This research project was supported by Isfahan University of Medical Sciences (IUMS), Isfahan, Iran.

\section{Availability of data and materials}

The datasets used and/or analyzed during the current study are only available to the corresponding author upon reasonable request.

\section{Ethics approval and consent to participate}

written informed consent was signed by every patient or her/his legally authorized representative prior to study participation. The Ethics Committee of Isfahan University of Medical Sciences approved the protocol of this study.( Ethics ID: IR.MUI.RESEARCH.REC.1397.357)

\section{Consent for publication}

Not applicable

\section{Competing interests}

The authors declare that they have no competing interests.

\section{Author details}

1- Department of Community Nutrition, School of Nutrition and Food Sciences, Isfahan University of Medical Sciences, Isfahan, Iran. 2- Department of Biostatistics and Epidemiology, School of Health, Isfahan University of Medical Sciences, Isfahan, Iran.3- Medical School, Lorestan University of Medical Sciences, Lorestan, Iran.

\section{Abbreviations}

CHD: Coronary Heart Diseases, CAD: Coronary artery diseases, MDA: Malondialdehyde,

TAC: Total Antioxidant Capacity, FFQ: Food Frequency Questionnaire, IPAQ: international Physical Activity Questionnaires, UA: Uric acid, BMI: Body Mass Index, SBP: Systolic Blood Pressure, DBP: Diastolic Blood 


\section{References}

1. Sanchis-Gomar F, Leischik R, Lucia A.Epidemiology of coronary heart disease and acute coronary syndrome. Ann Transl Med. 2016;4(13):256.

2. Begheri $B$, et al. investigation of serum uric acid and severity of coronary artery involvement in angiography of chronic stable angina patients. J Mazandaran Univ Med Sci. 2012;22(98):19-26. Available from: http://jmums.mazums.ac.ir/article-1-1854-fa.html

3. Chiha M, Njeim M, and G, Chedrawy E. Diabetes and Coronary Heart Disease: A Risk Factor for the Global Epidemic. Int Jour Hyper. 2012;Article ID 697240,7 pages. Available from: https://www.ncbi.nlm.nih.gov/pubmed/23119148

4. Boroumand MA, Davoodi G, Amirzadegan A, Saadat S, Abbasi SH, et al. Correlation between lipoprotein(a) serum concentration and severity of coronary artery stenosis in an Iranian population according to Gensini score. Clin Biochem. 2008;41(3):117-20.

5. Daniel M AS, Caidahl K, Collste O, Ekenbäck C, Frick M, Y-Hassan S, Henareh L, Jernberg T, Malmqvist K, Schenck-Gustafsson K, Sörensson P, Sundin O, Hofman-Bang C, Tornvall P. Effect of Myocardial Infarction With Nonobstructive Coronary Arteries on Physical Capacity and Quality-of-Life. Am J Cardiol. 2017;120(3):341-6.

6. Hong EL, Seong HK, Eung JK, Jin WK, Seung WR. Clinical value of serum uric acid in patients with suspected coronary artery disease. KJIM. 2010;25(1):21-26.

7. Kim SY, Guevara JP, Kim KM, et al. Hyperuricemia and coronary heart disease: a systematic review and meta-analysis. Arthritis Care Res (Hoboken). 2010;62:170-180.

8. Wang Y, Chun OK, Song WO. Plasma and dietary antioxidant status as cardiovascular disease risk factors: a review of human studies. Nutrients. 2013;5(8):2969-3004.

9. Atkins JL, Whincup PH, Morris RW, Lennon LT, Papacosta O, Wannamethee SG. High Diet Quality Is Associated with a Lower Risk of Cardiovascular Disease and All-Cause Mortality in Older Men. The Journal of Nutrition. 2014;144:673-680.

10. Choi HK, Gao X, Curhan G. vitamin c intake and the risk of gout in men. Arch Intern Med. 2009;169:502-7.

11. Kayima J, Katamba A, Leontsini E, Nuwaha F. Hypertension awareness, treatment and control in Africa: a systematic review. BMC Cardiovascular Disorders. 2013;45(4):85-9.

12. Meshkani R, Zargari M, Larijani $B$. The relationship between uric acid and metabolic syndrome in normal glucose tolerance and normal fasting glucose subjects. Acta Diabetol. 2011;48(1):79-88.

13. Bagheri B, Zargari M, Meshkini F, Dinarvand K, Mokhberi V, Azizi S, Rasouli M. Uric Acid and Coronary Artery Disease, Two Sides of a Single Coin: A Determinant of Antioxidant System or a Factor in Metabolic Syndrome. J Clin Diagn Res. 2016;10(2):27-31. Available from: https://www.jcdr.net/article_fulltext.asp?id=7281 
14. Alderman M, Aiyer KJ. Uric acid: Role in cardiovascular disease and effects of losartan. Curr Med Res Opin. 2004;20:369-379.

15. Culleton BF, Larson MG, Kannel WB, Levy D. Serum uric acid and risk for cardiovascular disease and death: The Framingham Heart Study. Ann Intern Med. 1999;131:7-13.

16. Alderman MH. Uric acid and cardiovascular risk. Curr Opin Pharmacol. 2002;2:126-130.

17. Johnson RJ, Kang DH, Feig D, Kivlighn S, Kanelis J, Watanabe S, et al. Is there a pathogenetic role for uric acid in hypertension and cardiovascular and renal disease?. Hypertension. 2003;41:1183-90.

18. Jelic-Ivanovic Z, Memon L, Spasojevic Kalimanovska V, Bogavac-Stanojevic N, Spasic S. Independent association of high serum uric acid concentration with angiographically defined coronary artery disease. Tohoku J Exp Med. 2007;211:369-377.

19. Alderman M, Redfern JS. Serum uric acid: A cardiovasular risk factor?. Ther Umsch. 2004; 61:547552.

20. Baker JF, Krishnan E, Chen L, Schumacher HR. Serum uric acid and cardiovascular disease: Recent developments, and where do they leave us? Am J Med. 2005;118:816-26.

21. Kim SY, Guevara JP, Kim KM, et al. Hyperuricaemia and coronary heart disease: a systematic review and meta-analysis. Arthritis Care Res. 2010;62:170-80. Available from: https://onlinelibrary.wiley.com/doi/full/10.1002/acr.20065

22. Ekici B, Kütük U, Alhan A, Fehmi Töre $H$. The relationship between serum uric acid levels and angiographic severity of coronary heart disease. Kardiol Pol. 2015;73(7):533-38.

23. Goodarznejad HR, Sotoudeh Anvari M, Boroumand MA, Karimi AA, Abbasi SH, et al. Hyperuricemia and the presence and severity of coronary artery disease. Lab medicin. 2010; 41(1):40-45.

24. Kotake H, Sawada Y, Hoshio A, Shirota K, Tomokuni A, Doi T, et al. Relation between serum uric acid and angiographically defined coronary artery disease in postmenopausal women. J Med. 1992;23:409-15. Available from: https://www.ncbi.nlm.nih.gov/pubmed/1293251

25. Tuttle KR, Short RA, Johnson RJ. Sex differences in uric acid and risk factors for coronary artery disease. Am J Cardiol. 2001;87:1411-14.

26. Jelić-Ivanović Z, Memon L, Spasojević- Kalimanovska V, Bogavac-Stanojević N, Spasić S. Independent association of high serum uric acid concentration with angiographically defined coronary artery disease. Tohoku J Exp Med. 2007;211(4):369-77.

27. Yoo TW, Sung KC, Shin HS, Kim BJ, Kim BS, Kang JH, et al. Relationship between serum uric acid concentration and insulin resistance and metabolic syndrome. Circ J. 2005;69:928-33.

28. Tuomilehto J, Zimmet P, Wolf E, Taylor R, Ram P. Plasma uric acid level and its association with diabetes mellitus and some biologic parameters in a biracial population of Fiji. Am J Epidemiol. 1988;127:321-36.

29. Serdar Z, Aslan K, Dirican M, Sarandöl E, Yeşilbursa D, Serdar A. Lipid and protein oxidation and antioxidant status in patients with angiographically proven coronary artery disease. Clin biochem. 
2006; 39:794-803. Available from:

https://www.sciencedirect.com/science/article/pii/S0009912006000531?via\%3Dihub

30. Delport R, et al. Antioxidant Vitamins and Coronary Artery Disease Risk in South African Males. Clinica Chimica Acta.1998;278:55-60.

31. Nojiri S, Daida H, Mokuno H, Iwama Y, Mae K, Ushio F, et al. Association of serum antioxidant capacity with coronary artery disease in middle-aged men. Jpn Heart J. 2001;42:677-90.

32. Heitzer T, Schlinzig T, Krohn K, Meinertz T, Münzel T. Endothelial Dysfunction, Oxidative Stress and Risk of Cardiovascular Events in Patients with Coronary Artery Disease. Circulation. 2001;104:267378.

33. Atkins JL, Whincup PH, Morris RW, Lennon LT, Papacosta O, Wannamethee SG. High Diet Quality Is Associated with a Lower Risk of Cardiovascular Disease and All-Cause Mortality in Older Men. The Journal of Nutrition. 2014;144:673-80.

34. Simon AS, Chithra V, Vijayan A, Dinesh RD, Vijayakumar T. Altered DNA repair, oxidative stress and antioxidant status in coronary artery disease. J Bio sci. 2013;38:385-89.

35. Schisterman EF, Faraggi D, Brown R, et al. Minimal and best linear combination of oxidative stress and antioxidant biomarkers to discriminate cardiovascular disease. Nutr Metabol Cardiovasc Dis. 2002;12:259-66. Available from: https://www.ncbi.nlm.nih.gov/pubmed/12616805

36. Gawron-Skarbek A, Chrzczanowicz J, Kostka J, Nowak D, Drygas W, Jegier A, Kostka T. Cardiovascular Risk Factors and Total Serum Antioxidant Capacity in Healthy Men and in Men with Coronary Heart Disease. BioMed Res Int. 2014;Article ID 216964, 8 pages. Available from: https://www.ncbi.nlm.nih.gov/pubmed/25180177

37. Khaki Khatibi F, Yaghoubi A, Zarghami N, Rahbani M, Babaie H. Evaluation of hs-CRP, Antioxidant Markers and MDA in Patients of Coronary Artery Disease (CAD) Containing Non-Smokers and NonDiabetics. J Cardiovasc Thorac Res. 2010;2(4):13-18. Available from:

https://www.sid.ir/en/journal/ViewPaper.aspx?ID=189837

38. Stocker R, Keaney JF Jr. Role of oxidative modifications in atherosclerosis. Physiol Rev. 2004;84:1381-1478.

39. Uppal N, Uppal V, Uppal P. Progression of Coronary Artery Disease (CAD) from Stable Angina (SA) Towards Myocardial Infarction (MI): Role of Oxidative Stress. J Clin Diagn Res. 2014;8(2):40-3.

40. Lee BJ, Lin YC, Huang YC, Ko YW, Hsia S, Lin PT. The relationship between coenzyme Q10, oxidative stress, and antioxidant enzymes activities and coronary artery disease. Sci World J. 2012; Article ID 792756, 8 pages. Available from: https://www.ncbi.nlm.nih.gov/pubmed/22645453

41. Mutlu-Turkoglu U, Akalin Z, Ilhan E, Yilmaz E, Bilge A, Nisanci Y, et al. Increased plasma malondialdehyde and protein carbonyl levels and lymphocyte DNA damage in patients with angiographically defined coronary artery disease. Clin Biochem. 2005;38:1059-65.

\section{Tables}


Table 1: Mean age, height, weight, BMI, physical activity and BP of the two groups

\begin{tabular}{|c|c|c|c|c|c|}
\hline \multirow{2}{*}{ Variable } & \multicolumn{2}{|c|}{ Patients group (case) } & \multicolumn{2}{c|}{ Healthy groups (control) } & \multirow{2}{*}{$\mathrm{p}$} \\
\cline { 2 - 4 } & Mean & SD & Mean & SD & \\
\hline Age (year) & 58.5 & 8.1 & 56.2 & 8.5 & 0.2 \\
\hline Height $(\mathrm{cm})$ & 167.3 & 8.4 & 167.7 & 10.2 & 0.82 \\
\hline Weight $(\mathrm{kg})$ & 74.9 & 13.5 & 75.3 & 11.1 & 0.9 \\
\hline BMI (kg/m2) & 26.9 & 5.1 & 26.7 & 3.03 & 0.86 \\
\hline Physical activity (MET.h/wk) & 1017.3 & 181.3 & 1302 & 181.3 & 0.027 \\
\hline systolic BP (mmHg) & 12.5 & 1.4 & 11.8 & 1.5 & 0.028 \\
\hline Diastolic BP (mmHg) & 7.9 & 0.9 & 7.7 & 1.1 & 0.39 \\
\hline
\end{tabular}

Table 2: Frequency of the qualitative variables of the two groups

\begin{tabular}{|c|c|c|c|c|c|c|}
\hline \multirow{2}{*}{\multicolumn{2}{|c|}{ Variable }} & \multicolumn{2}{|c|}{$\begin{array}{l}\text { Patients group } \\
\text { (case) }\end{array}$} & \multicolumn{2}{|c|}{$\begin{array}{l}\text { Healthy group } \\
\text { (control) }\end{array}$} & \multirow[t]{2}{*}{$\mathrm{P}$} \\
\hline & & frequency & $\%$ & frequency & $\%$ & \\
\hline \multirow[t]{2}{*}{ Sex } & Men & 27 & 61.4 & 26 & 59.1 & \multirow[t]{2}{*}{0.83} \\
\hline & Women & 17 & 38.6 & 18 & 40.9 & \\
\hline \multirow[t]{2}{*}{ Marital status } & Single & 1 & 2.3 & 0 & 0 & \multirow[t]{2}{*}{0.5} \\
\hline & Married & 43 & 97.7 & 44 & 100 & \\
\hline \multirow{5}{*}{ Job } & Clerk & 9 & 20.5 & 9 & 20.5 & \multirow{5}{*}{0.24} \\
\hline & housewife & 15 & 34.1 & 17 & 38.6 & \\
\hline & Worker & 3 & 6.8 & 7 & 15.9 & \\
\hline & Farmer & 10 & 22.7 & 4 & 9.1 & \\
\hline & Other & 7 & 15.9 & 7 & 15.9 & \\
\hline \multirow{5}{*}{$\begin{array}{l}\text { Background } \\
\text { diseases }\end{array}$} & No history & 26 & 59.1 & 25 & 56.8 & \multirow{5}{*}{0.37} \\
\hline & hypertension & 10 & 22.7 & 6 & 13.6 & \\
\hline & $\begin{array}{l}\text { Hypertension and } \\
\text { hyperlipidemia }\end{array}$ & 5 & 11.4 & 9 & 20.5 & \\
\hline & Hyperlipidemia & 2 & 4.5 & 4 & 9.1 & \\
\hline & Cardiac disorders & 1 & 2.3 & 0 & 0 & \\
\hline \multirow{2}{*}{$\begin{array}{l}\text { Residence } \\
\text { region }\end{array}$} & City & 31 & 70.5 & 28 & 63.6 & \multirow[t]{2}{*}{0.5} \\
\hline & Village & 13 & 29.5 & 16 & 36.4 & \\
\hline \multirow[t]{3}{*}{ Education level } & Below diploma & 33 & 75 & 29 & 65.9 & \multirow[t]{3}{*}{0.26} \\
\hline & Diploma & 9 & 20.4 & 9 & 20.4 & \\
\hline & Bachelor and higher & 2 & 4.6 & 6 & 13.7 & \\
\hline \multirow{2}{*}{\multicolumn{2}{|c|}{ Smoking }} & 12 & 27.3 & 3 & 6.8 & 0.01 \\
\hline & & 44 & 100 & 22 & 50 & $<0.001$ \\
\hline
\end{tabular}

Table 3: Mean dietary antioxidant intake in the two groups 


\begin{tabular}{|c|c|c|c|c|c|}
\hline \multirow{2}{*}{ Nutrients } & \multicolumn{2}{|c|}{ Patient group (case) } & \multicolumn{2}{|c|}{ Healthy group (control) } & \multirow{2}{*}{ P } \\
\cline { 2 - 5 } & Mean & SD & Mean & SD & \\
\hline Vitamin A $(\mu \mathrm{g})$ & 340.9 & 68.9 & 338.5 & 84.7 & 0.88 \\
\hline Beta carotene $(\mu \mathrm{g})$ & 1492.9 & 367.1 & 1359.01 & 348.5 & 0.08 \\
\hline Vitamin C $(\mathrm{mg})$ & 69.1 & 22.5 & 61.4 & 11.7 & 0.047 \\
\hline Vitamin E $(\mathrm{mg})$ & 7.6 & 1.5 & 7.4 & 1 & 0.53 \\
\hline Zinc $(\mathrm{mg})$ & 7.3 & 1.2 & 7.8 & 1.1 & 0.14 \\
\hline Selenium $(\mu \mathrm{g})$ & 75.7 & 15.6 & 80.6 & 13.6 & 0.12 \\
\hline
\end{tabular}

Table 4: The comparison of the Mean \pm SD of biochemical markers in the case and control groups

\begin{tabular}{|c|c|c|c|c|c|}
\hline \multirow{2}{*}{ Variable } & \multicolumn{2}{|c|}{ Patient group (case) } & \multicolumn{2}{c|}{ Healthy group (control) } & \multirow{2}{*}{ P } \\
\cline { 2 - 5 } & Mean & SD & Mean & SD & \\
\hline Vitamin C (ug/ml) & 59.8 & 19.1 & 71.8 & 18.6 & 0.03 \\
\hline Uric acid $(\mathrm{mg} / \mathrm{dl})$ & 5.9 & 1.3 & 4.7 & 1.2 & $<0.001$ \\
\hline Total antioxidant capacity $(\mathrm{nmol} / \mathrm{ml})$ & 1155.5 & 190.1 & 1079.1 & 183.3 & 0.06 \\
\hline Malondialdehyde $(\mathrm{nmol} / \mathrm{ml})$ & 0.2 & 0.04 & 0.21 & 0.06 & 0.25 \\
\hline
\end{tabular}

Table 5: Pearson correlation coefficient between UA level and other variables

\begin{tabular}{|c|c|c|}
\hline \multirow{2}{*}{ Variable } & \multicolumn{2}{|c|}{ Uric acid } \\
\cline { 2 - 3 } & $\mathrm{R}$ & $\mathrm{P}$ \\
\hline Serum Vitamin C & -0.011 & 0.92 \\
\hline Serum TAC & 0.370 & $<0.001$ \\
\hline Serum MDA & -0.045 & 0.68 \\
\hline Vitamin A intake & -0.229 & 0.03 \\
\hline Beta carotene intake & 0.06 & 0.58 \\
\hline Vitamin C intake & 0.065 & 0.55 \\
\hline Vitamin E intake & -0.109 & 0.31 \\
\hline Zinc intake & -0.311 & 0.003 \\
\hline Selenium intake & -0.305 & 0.004 \\
\hline
\end{tabular}

